\title{
BIOBADABRASIL: SAFETY PROFILE OF THE FIRST BIOLOGICAL AGENT OR JAK INHIBITOR FOR THE TREATMENT OF RA
}

Markus Bredmeir ${ }^{1}$, Angela Luzia Branco P Duarte², Marcelo de Medeiro Pinheiro ${ }^{3}$, Barbara Standler Kahlow ${ }^{4}$, José Caetano Macieira ${ }^{5}$, Roberto Ranza ${ }^{6}$, José Roberto Silva Miranda ${ }^{7}$, Gláucio Ricardo Werner de Castro ${ }^{8}$, Valéria Valim Cristo ${ }^{9}$, Manoel Barros Bértolo ${ }^{10}$, Maria de Fatima Lobato da Cunha Sauma ${ }^{11}$, Vander Fernandes ${ }^{12}$, Ana Cristina de Medeiros Ribeiro ${ }^{13}$, Reginaldo Botelho Teodoro ${ }^{14}$, Claiton Viegas Brenol ${ }^{15}$, Deborah Negrão Gonçalo Dias ${ }^{16}$, Hellen Mary da Silveira de Carvalho ${ }^{17}$, Sâmia Studart ${ }^{18}$, José Carlos Amaral ${ }^{4}$, Geraldo da Rocha Castelar Pinheiro ${ }^{19}$, Laurindo Rocha Junior ${ }^{20}$, Ivanio Alves Pereira ${ }^{21}$, Morgana Ohira Gazzeta ${ }^{22}$, Adriana Maria Kakehas ${ }^{123}$, Paulo Lozada Junior ${ }^{24}$, André Luiz Shinji Hayata ${ }^{25}$, Inês Guimarães da Silveira ${ }^{26}$, Cristiano Michelini Lupo ${ }^{27}$, Helena Lucia Alves Pereira ${ }^{28}$, Rina Dalva Neubarth Giorgi ${ }^{29}$, Morton A. Scheinberg ${ }^{30}$, Flavio Sztajnbok ${ }^{20}$, David Cezar Titton ${ }^{16}$, Aline Ranzolin ${ }^{2}$, Sergio Kowalski ${ }^{16}$, leda Maria Magalhães Laurindo ${ }^{31, \star}$, José Roberto Prevenza ${ }^{32}$

1.Universidade Federal do Rio Grande do Sul, Porto Alegre (RS), Brazil, 2. Universidade Federal de Pernambuco, Recife (PE), Brazil, 3. Universidade Federal de São Paulo, São Paulo (SP), Brazil, 4. Hospital Universitário Evangélico, Curitiba (PR), Brazil, 5. Universidade Federal de Sergipe, Aracajú (SE), Brazil, 6. Universidade Federal de Uberlândia, Uberlândia (MG), Brazil, 7. Artrocenter Clínica Médica Ltda, São Paulo (SP), Brazil, 8. Hospital Governador Celso Ramos, Florianópolis (SC), Brazil, 9. Universidade Federal do Espírito Santo, Vitória (ES), Brazil, 10. Universidade Estadual de Campinas, Campinas (SP), Brazil, 11. Universidade Federal do Pará, Belém (PA), Brazil, 12. Hospital Geral Universitário, Cuiabá (MT), Brazil, 13. Universidade de São Paulo, São Paulo (SP), Brazil, 14. Universidade Federal do Triângulo Mineiro, Uberaba (MG), Brazil, 15. Hospital de Clínicas de Porto Alegre, Porto Alegre (RS), Brazil, 16. Universidade Federal do Paraná, Curitiba (PR), Brazil, 17. Hospital de Base, Brasília (DF), Brazil, 18. Hospital Geral de Fortaleza, Fortaleza (CE), Brazil, 19. Universidade do Estado do Rio de Janeiro, Rio de Janeiro (RJ), Brazil, 20. Fundação Martiniano Fernandes, Recife (PE), Brazil, 21. Universidade Federal de Santa Catarina, Florianópolis (SC), Brazil, 22. Santa Casa de Misericórdia, Rio de Janeiro (RJ), Brazil, 23. Universidade Federal de Minas Gerais, Belo Horizonte (MG), Brazil, 24. Hospital de Clínicas de Ribeirão Preto, Ribeirão Preto (SP), Brazil, 25. Clínica de Reumatologia de Osasco, São Paulo (SP), Brazil, 26. Pontifícia Universidade de Porto Alegre, Porto Alegre (RS), Brazil, 27. Faculdade de Medicina de São José do Rio Preto, São José do Rio Preto (SP), Brazil, 28. Universidade Federal do Amazonas, Manaus (AM), Brazil, 29. Hospital do Servidor Público de São Paulo, São Paulo (SP), Brazil, 30. Hospital Abreu Sodré, São Paulo (SP), Brazil, 31. Universidade Nove de Julho, São Paulo (SP), Brazil, 32. Pontifícia Universidade Católica de Campinas, Campinas (SP), Brazil.

*Corresponding author: frlaurindo@uol.com.br

\section{BACKGROUND}

After failure of conventional synthetic disease modifying antirheumatic drugs (csDMARDs) in the therapy of rheumatoid arthritis (RA), treatment may be escalated to a biological DMARDs (bDMARDs) or JAK inhibitors (JAKi). However, the use of bDMARDs, especially anti-TNF agents, has been associated with higher risk of serious infections in comparison to csDMARDs. Recently, other anti-TNF agents have been introduced in the market, and non-anti-TNF-biologics/JAKi can also be used as first-line advanced therapy in RA. So, our aim in the present study is to evaluate the safety profile of the first biologic/JAKi used in the therapy of RA in our setting.

\section{MATERIALS AND METHODS}

BiobadaBrasil is a multicentric prospective cohort study of patients with rheumatic diseases starting their first bDMARD/ JAKi or a csDMARD. The present analysis includes RA patients recruited from January 2009 to November 2019, followed-up over the first course of treatment with a bDMARD/JAKi until censoring (latest date, November 19, 2019) or occurrence of the outcome of interest. The primary outcome was the incidence of serious AE (SAE) of any kind. Secondary outcomes were serious infectious. Multivariate Cox proportional hazards models were used to estimate hazard ratios (HR) and $95 \%$ confidence intervals (Cls).

\section{RESULTS}

In total, 1351 patients (4180 patient-years [PY]) were enrolled. The overall incidence of SAEs was 6.1/100 PY. Adalimumab was the most frequently prescribed agent, followed by infliximab $(n=362)$. The hazard of SAE and serious infections comparing with infliximab is described in Table 1.

\section{CONCLUSION}

In our study, infliximab presented a higher hazard of SAE comparing with most other anti-TNF agents and tofacitinib. 
Table 1. Hazard of SAE of each therapeutic agent comparing with infliximab. Results are $\mathrm{HR}, 95 \% \mathrm{Cls}$, and $\mathrm{P}$ values.

\begin{tabular}{|c|c|c|}
\hline bDMARD/JAKi (No. patients) & SAE (255 events) & Infectious SAE (134 events) \\
\hline Adalimumab (407) & 0.66 (0.49 to 0.91$), p=0.010$ & 0.54 ( 0.15 to 0.83 ), $p=0.005$ \\
\hline Etanercept (276) & 0.64 ( 0.46 to 0.91$), p=0.014$ & 0.54 ( 0.34 to 0.87$), p=0.011$ \\
\hline Certolizumab (80) & 0.40 (0.16 to 0.96), $p=0.039$ & 0.30 (0.09 to 1.04$), p=0.057$ \\
\hline Tofacitinib (59) & 0.09 (0.01 to 0.65$), p=0.012$ & Not done \\
\hline Rituximab (53) & 0.60 (0.30 to 1.22$), p=0.161$ & 0.24 ( 0.07 to 0.82 ), $p=0.023$ \\
\hline Golimumab (53) & 0.47 (0.18 to 1.19), $p=0.111$ & 0.30 (0.07 to 1.30$), p=0.108$ \\
\hline Abatacept (32) & 0.53 ( 0.19 to 1.49$), p=0.229$ & 0.53 ( 0.15 to 1.84 ), $p=0.315$ \\
\hline Tocilizumab (29) & 1.14 (0.53 to 2.46$), p=0.733$ & 1.47 (0.57 to 3.81), $p=0.427$ \\
\hline
\end{tabular}

